\title{
Climbing the Social Ladder: Physiological Response to Social Status in Adolescents
}

\author{
Amber R. Massey • Jennifer Byrd-Craven • \\ Brandon J. Auer • CaSandra L. Swearingen
}

Received: 29 June 2014 /Revised: 12 September 2014 / Accepted: 17 September 2014 /Published online: 10 October 2014 (C) Springer International Publishing 2014

\begin{abstract}
Social hierarchies and physiology are intricately linked, but these associations have not been well studied in adolescence, typically a time of increased focus on social status. Three studies were conducted to better understand the relationship between social dominance, personality and related physiological responses of adolescents upon hierarchy formation and after hierarchies were established. Heart rate and salivary cortisol were used as indices of physiological reactivity. Study one investigated the relationship between, social dominance rank, personality and social strategy usage. Study two extended study one with the addition of a reward allocation task and examined heart rate change. Study three examined social strategy use and salivary cortisol changes in response to a reward allocation task. Overall findings suggest that a combination of prosocial and coercive behaviors is seen in individuals that are perceived as socially dominant, especially in established hierarchies. Subordinates had a greater physiological response to the reward allocation task, but sex differences impacted these results. The current study provides a better understanding of physiological and behavioral profiles of socially prominent adolescents, and how this may differ by sex.
\end{abstract}

Keywords Social dominance $\cdot$ Stress $\cdot$ Cortisol $\cdot$ Social strategies $\cdot$ Reward allocation task

\section{Introduction}

Social dominance involves hierarchical group-based systems of inequality (Pratto et al. 1994) often related to the dispersing of resources, whether they are material or social. Challenges related to social dynamics and striving for social resources activate physiological responses associated with brain and behavior changes aimed at managing these challenges (Flinn 2006; Sapolsky 2005). These psychosocial challenges are particularly salient during adolescence, a time of establishing and maintaining social bonds and status (Ellis et al. 2012). The hypothalamic-pituitary-adrenal (HPA) axis and

\footnotetext{
A. R. Massey $(\bowtie) \cdot J$. Byrd-Craven • B. J. Auer • C. L. Swearingen

Department of Psychology, Oklahoma State University, Stillwater, OK 74078, USA

e-mail: masseya@ostatemail.okstate.edu
} 
the autonomic nervous system (ANS) work in concert to enable individuals to manage the challenge by allocating energy and cognitive resources. Both systems are influenced by social dynamics, in particular social exclusion (Stroud et al. 2009), although they show different response patterns (Frankenhaeuser 1982; Peters et al. 1998).

Certain personality characteristics and the use of social strategies are associated with dominance within a hierarchy (Hawley 2003a, b; Roseth, et al. 2011; Van der Linden et al. 2010). Social status, especially in conjunction with personality characteristics and stability of hierarchies, may activate the stress response system (Fortunato et al. 2008; Gesquiere et al. 2011; Kivlighan and Granger 2006; Ostner et al. 2008; Sapolsky 2004). However, studies have produced mixed results related to the patterning of stress system activity. For example, some studies have shown that dominant individuals exhibit stronger HPA and ANS response (Davis et al. 1999; Hellhammer et al. 1997; Kivlighan and Granger 2006; Poisbleau et al. 2005; Sapolsky 2004) while others have shown subordinate individuals to be more physiologically reactive (Chamove and Bowman 1978; Fox, et al. 1997; Ostner, et al. 2008; Stroud, et al. 2009). In some instances, rank increase was associated with reduced HPA axis activation. In addition, much of previous literature has focused on only one sex, limited age groups, novel stress situations, chronic stress situations, or aggressive stress situations, all of which limit the generalizability of the findings. Therefore, it is important to examine the human social structure in real world situations in order to better elucidate the relationship between status and stress response activity. The current set of studies addresses the discrepancy in previous results by focusing on adolescents in a realistic resource control situation. During adolescence, the importance of status reaches its peak and social dominance may begin to crystallize (Pellegrini, et al. 2011). This is the first known study to integrate resource control theory and physiological reactivity in adolescents to attempt to tease out these relationships.

\section{Social Dominance and Social Strategies}

Social dominance involves leadership and prominence or visibility within the hierarchy (Hawley 2014). It also involves appropriate strategy usage in order to control and manipulate social resources within the hierarchy (Hawley 2014). Hawley and colleagues have defined five resource control strategy types based on social strategy usage: noncontrollers, typical controllers, prosocial controllers, coercive controllers, and bistragetic controllers (Hawley 2003a, b). Hawley defines these groups based on self-reported, peer-reported, or parent/teacher-reported use of prosocial and coercive strategies for resource obtainment. Resources may be anything from money, time, support, or assistance. For example, often individuals that are bi-strategic will both assist others and control others in order to gain and maintain the resources they are interested in. This bi-strategic behavior often leads to the individual not necessarily being liked by most, but being perceived as popular, in other words, socially prominent or dominant. Bi-strategic individuals are rated by peers as being high on intimacy and fun, but also high on conflict and aggression (Hawley et al. 2007). It is, perhaps, this social strategy that might be most interesting in terms of effective control of social resources and associated physiological correlates due to their social focus, flexible strategy use, and ability to effectively wield social power (Hawley et al. 2002). 


\section{Variations in Sensitivity to Stress and Social Hierarchies}

The autonomic nervous system (ANS) often responds to general threats and stressors by acting as the control system to visceral functioning in areas such as heart rate, digestion, respiratory rate, salivation, perspiration, pupillary dilation, urination, and sexual arousal (Berntson et al. 1991). The ANS is activated by both positive affect and affliative behaviors (Fortunato et al. 2008), as well as, negative affect (Spinrad et al. 2007).

One of the most widely used measures of ANS is heart rate. In particular heart rate change is used to study emotion-inducing content (Eisenberg, et al. 1989). Reduction of the heart rate may reflect greater parasympathetic activity, reduced sympathetic activity, or some combination, and is often related to sadness, empathy, attention, or encoding of information (Kreibig, et al. 2007). Social stressors, such as unexpected social rejection, have been associated with heart rate deceleration (Gunther Moor et al. 2010). Individuals with low emotional reactivity, high endurance, or high sensory sensitivity were shown to have slower heart rates after observing positive words (De Pascalis et al. 1999). However, other studies have shown that temperament alone is not causally related to heart rate changes. Introverts display more pronounced heart rate changes in response to punishment signals while extraverts displayed greater heart rate changes in response to reward signals (De Pascalis et al. 1996). Thus, it appears heart rate as a measure of ANS activity is dependent upon situtional context as well as temperament characteristics.

ANS activation also appears to be related to social status. ANS activity (indexed by salivary alpha-amylase) was shown to be related to social affiliation, dominance, and interest in team bonding in collegiate athletes (Kivlighan and Granger 2006). Low social power or status has been seen to elicit higher blood pressure during the process of evaluating status while high social status elicits an increase in blood pressure when change in status takes place (Scheepers and Ellemers 2005). Additionally, Cloutier et al. (2013) found that higher subjective status was related negatively to heart rate variability. Taken together, it appears that social status and stability of the hierarchy can impact ANS activation.

The HPA axis is differentiated from the ANS in that it is typically slower to respond and is more specific to threat and opportunities within social dynamics (Nesse et al. 2007). In particular, social hierarchies represent a specific source of psychosocial challenge that has been associated with neuroendocrine reactivity (Flinn 2006; Sapolsky 2004). HPA axis activity associated with hierarchies can vary as a function of personality, sex, social structure, and stability of the hierarchy (Boyce and Ellis 2005; Ellis and Del Giudice 2014). For example, human physiological responses to social contexts, as indexed by cortisol levels, were found to be associated with temperament in elementary school children in relation to starting a new school year (Bruce et al. 2002; Davis, et al. 1999). In particular, extroverted children had the largest cortisol response in the first few days of school, potentially reflecting their arousal and perception of social opportunities (Nesse, et al. 2007).

Cortisol levels may also differ in relation to hierarchy stability, as demonstrated in the animal literature (Sapolsky 2004). Human female hierarches are often less stable than those of males (Geary et al. 2003; Savin-Williams 1978). In addition, the top hierarchical positions are distinguished from other positions by their higher concentrations of cortisol (Sapolsky 2004). By examining both ANS and HPA activation in 
response to social hierarchies, a more comprehensive view of how these systems assist in coping with social challenges may be obtained

\section{Sex Differences}

Sex differences have consistently been reported in relation to stress system reactivity (Hellhammer, et al. 2009; Taylor 2006). Adolescence is also a time in the life-span in which sex differences in social behavior are often exaggerated (Geary 2010). The relative lack of stability in female hierarchies may impact how physiological responses to these dynamic social contexts are regulated (Savin-Williams 1979). Same-sex female peer relationships are characterized by increased monitoring to avoid losing social support (Benenson and Christakos 2003; Geary et al. 2003), and may also be more likely to involve a social style based on tending and befriending in response to stress as opposed to the more male-typical fight-or-flight stress response system (Taylor 2006; see also Geary and Flinn 2002). While stress hormones are often reduced as a result of social support gained from close relationships, perceived gaps or unavailability of social support can lead to an increase stress system activity (Taylor and Master 2011).

The literature on males has been fairly consistent. In general it shows that males use more physical aggression and engage in more direct competition in order to gain resources than females do. Geary and colleagues (2003) proposed that accompanying selection pressures (for example, male philopatry) for boys and men favored the evolution of large, competitive coalitions and this results in the formation of withincoalition dominance hierarchies. More specifically, males create groups and cooperate within groups in order to gain valuable resources from others. Thus, social dominance is related to both aggression and coalitional support (Flinn et al. 2007).

In one study of 4th and 5th grade students, it was found that for boys non-verbal aggression was associated with decreased status while high levels of verbal and overt aggression were associated with increased status. For girls, only a high level of nonverbal aggression (in this case relational aggression), such as ignoring others or withholding friendship, was associated with status (Blake et al. 2011). These studies demonstrate the different dynamics of the hierarchies of males and females, and how they can necessitate different behavioral strategies for gaining and maintaining status.

\section{The Current Studies}

The goal of the current research is to examine the relationship between dominance, social strategy usage, personality traits, and stress response to social hierarchical interactions in an adolescent sample. The use of three studies allowed us to examine social strategy usage with established and unestablished hierarchies, in conjunction with heart rate and cortisol response. Study one identified the social strategies and personality traits that were important in social hierarchies among adolescents. Study two built on this information and examined ANS responses (via heart rate) to social hierarchical interactions. Study three used more established hierarchies to examine the relationship between social strategies, personality traits, and cortisol response to social hierarchical interactions. 


\section{Hypotheses}

It is expected that individuals ranked as socially dominant by their peers would score higher on bi-strategic controlling strategies, (Hawley 2003a, b; Hawley, et al. 2007), extroversion/surgency (van der Linden et al. 2010) and openness to experience (Akrami, and Ekehammar 2006). Additionally, they were expected to have the greatest change in cortisol levels after the reward allocation task. In addition, sex differences were expected, with females showing a stronger HPA response to the experimental social interaction than males (Stroud et al. 2002), and dominant females showing the strongest cortisol response because of their increased focus on being socially visible (see Hawley, et al. 2002).

\section{Common Method}

\section{Materials and Procedure}

All three studies used the following self-report questionnaires: the Resource-Control Strategies Inventory (RSCI) (Hawley 2003a, b; 2007; 2014). The first study also employed the use of this questionnaire as a measure of others use of resource strategies. In particular, individuals rated dominant individual's strategy usage. The Resource Strategies Control Inventory (Hawley 2003a, b) was used in order to determine if dominant individuals use prosocial strategies, coercive strategies, bi-strategic strategies, relational aggression, or overt aggression. Prosocial behaviors were assessed based on two questions (i.e. He/She has good ideas or suggestions that others like to follow; Hel She is chosen by others to lead the group). Coercive reported behaviors were also assessed based on two questions (i.e. He/She makes others do what he/she wants; Hel She forces others to follow their plans). The scores for bi-strategic controllers were configured using the sum of prosocial questions and coercive questions. This method is a deviation from previous work by Hawley $(2003 a, b)$ in which percentiles were used. Due to the small sample size, summed scores from participants' use of both strategies was used for this study. Relational aggression was assessed based on three questions (i.e. He/She gossips or spreads rumors about others if he/she is mad at them). Finally, overt aggression was assessed based on three questions (i.e. He/She pushes, kicks, or punches other because he/she has been angered by them).

Due to time constraints in Studies One and Three, the ten-item personality inventory (TIPI) (Gosling et al. 2003) that assessed the big five dimensions of personality (Openness, Conscientiousness, Extraversion, Agreeableness, Emotional Stability) was used, while the Rothbart Early Adolescent Temperament Questionnaire-Revised Short Form (Capaldi and Rothbart 1992) was used in Study 2. It consists of twelve subscales including activation control, affiliation, attention, fear, frustration, high intensity pleasure, inhibitory control, pleasure sensitivity, perceptual sensitivity, shyness, aggression, and depressive mood. The subscales scores can be combined to obtain four principal factors: effortful control, surgency, negative affect, and affiliativeness. Subscale reliabilities range from .65 to .82 (Capaldi and Rothbart 1992).

In addition, participants were given a list of all members in their group and were asked to rank all individuals as popular or not popular on a 5-point Likert scale with a 
score of one indicating "not popular" and five indicating "very popular." Previous literature has shown perceived popularity rankings to be overlapping with social dominance for adolescents especially when referring to the use of social strategies (Hawley et al. 2007). Therefore, for clarity, social dominance is used in the remainder of this paper.

\section{Participants}

In Studies One and Two adolescents in grades 7-10 were assessed at the beginning of a summer camp in the central United States, and again at the end of camp. Participants did not know each other upon entering camp. All members of the camp were asked to participate through informed consent distributed to parents and informed assent given to adolescents during camp orientation.

\section{Study One}

The purpose of this preliminary study was to examine how social dominance, personality, and social strategies are related in adolescents. This study examined dominance at the beginning and end of a two-week summer camp in order to better understand characteristics that are initially important for dominance as well as characteristics that become important to maintain that position overtime.

\section{Specific Hypothesis}

Individuals ranked as socially dominant by their peers were expected to score higher on bi-strategic controlling strategies as seen in Hawley and colleagues' work $(2003 ; 2007)$. In addition, individuals ranked as dominant by their peers were expected to score higher in personality traits such as extroversion and openness (Akrami and Ekehammar 2006; van der Linden et al. 2010).

\section{Study One Methods}

\section{Participants}

Participants were 31 adolescents taking part in a two-week summer camp in the central United States.

\section{Materials and Procedures}

One the first day of camp, participants were asked to complete questionnaires about themselves and rank others' popularity as a proxy for social dominance (see Common Method above). At the end of camp (2 weeks after camp started), participants were once again given a list of all campers and were asked to rank all individuals as popular or unpopular. In addition, participants were asked to list two individuals they felt were dominant and answer a series of questions about those individuals' social strategies. 
Study One Results

Average dominance rankings from the beginning of camp and the end of camp 2 weeks later were significantly correlated $(r=.57, p=.00)$. A series of regression equations were run to determine whether personality and social strategy predicted dominance. Personality scores for Openness predicted individuals dominance rankings at the beginning of camp $(F(1,28)=5.26, p=.03, \beta=.41)$. Dominance was not related to Extraversion $(F(1,28)=$ 2.39, $p=.14 ., \beta=.30)$, Conscientiousness $(F(1,28)=.17, p=.68, \beta=.08)$, Agreeableness $(F(1,28)=.49, p=.49, \beta=.14)$, Emotional Stability $(F(1,28)=1.57, p=.22, \beta=.24)$, selfreported prosocial strategy usage $(F(1,28)=1.15, p=.29, \beta=.20)$, or self-reported coercive strategy usage $(F(1,28)=.42, p=.52, \beta=.12)$. However, the more an individual ranked themselves a dominant, the more they viewed other dominant individuals as using not using overt and relational aggression. Specifically, dominance was negatively related to reporting other dominant individuals use of overt aggression $(\mathrm{F}(1,28)=9.35, p=.01$, $\beta=-.51)$ and relational aggression $(F(1,28)=7.88, p=.01 ., \beta=-.48)$.

\section{Study One Discussion}

Individuals observed to be dominant did not report using coercive strategies or prosocial strategies more frequently than others. This was not consistent with our hypothesis; however, coercive strategies may not have been appropriate for the short amount of time in which this group was formed. In addition, previous literature has suggested that prosociality may be observed more often early in youth based on the social learning theory and domain-specific, as well as, domain-general processes of cultural learning (O'Brein 2014). Therefore, this group may be in an intermediate age when both strategies are not quickly used or observed during new hierarchical formation. It is also possible that there was not a desirable resource or set of resources that elicited typical social strategy usage, an issue addressed in Study 2. Dominance rankings were consistent over time. Consistent with previous findings, dominance was related to openness to experience (Akrami and Ekehammar 2006). However, extroversion was not a significant predictor of dominance in this study. This study also showed that dominant individuals identified other dominant individuals as not using relational and overt aggression. It may be that dominant individuals perceive aggression differently than non-dominant individuals. Perhaps they employ the same strategy but, do not identify it as an aggressive act. This interpretation is consistent with previous research has showing that friends show not only similar levels of status but, similar use of aggressive acts as well (Rose et al. 2004).

\section{Study Two}

The purpose of this study was to better understand the relationship between social hierarchies, personality/temperament, social strategies, and physiological arousal in adolescents. This study involved a physiological measure of heart rate to reflect ANS responses to a reward allocation task, intended to mimic the social nuances of dispersing resources in everyday life. This research attempted to replicate and extend the previous study by investigating personality characteristics and physiological arousal associated with social dominance in adolescents. 


\section{Specific Hypothesis}

Individuals who self-reported being dominant were expected to score higher on bistrategic controlling strategies, consistent with Hawley and colleagues' work (2003; 2007). Those who reported themselves as low in dominance were expected to have the greatest change in heart rate during an experimental social interaction task (reward allocation task) due to the potential for loss of social resources or negative evaluation of themselves and the situation (Scheepers and Ellemers 2005).

\section{Study Two Methods}

\section{Participants}

Participants were 50 adolescents (males $=29$, females $=21$ ), ranging in age from 12 to 15 years participating in a 1 week summer camp in the central U.S. Parents reported income ranged from $\$ 10,000$ to $\$ 100,000$ with the average income range being between $\$ 61,000$ and $\$ 80,000$. No ethnicity data was recorded. They were randomly divided into groups of five by the camp director (not involved in this study) in order to participate in the weeks' activities. These groupings were used throughout the study.

\section{Materials and Procedures}

On the first day of camp, participants were asked to complete questionnaires (see common method). They then participated in a reward allocation task in which they disperse resources in a social situation. The predetermined camp groups were used as an existing social group or hierarchy. The task involved students being given $\$ 50$ dollars in $\$ 10$ increments. They were told to distribute it to their peers any way they preferred. All participants were given a turn to disperse the money. They then repeated the task with uneven increments of money (\$60 and $\$ 70$ ), in order to force unequal distribution. Participants were informed that a record was being kept of how the money was distributed. This group dynamic was used to mimic everyday stressors that are created from the need to control and disperse resources. Heart rate was taken from Omron 7 series digital blood pressure and heart rate wrist monitors (model number BP652) that were tested before the study for accuracy. Participants were informed that heart rate would be taken at three time points during the task. Each time a measurement was required, the experimenter asked participants to sit upright and position their hand and arm across their heart. Heart rate was taken from the digital wrist machines per machine instructions. Heart rate was taken before the task (time 1; approximately $5 \mathrm{~min}$ after entry), half way through the task (time 2; approximately 5 min later), and when the task was completed (time 3; approximately $5 \mathrm{~min}$ after time 2). On average, the task lasted approximately $15 \mathrm{~min}$ (See Fig. 1). Heart rate change scores were figured by subtracting the heart rate at time one from the heart rate at time three. Participants that received the most money were awarded a candy prize. On the final day of camp, the reward allocation task was repeated and heart rate was obtained as previously mentioned using the same groups. 


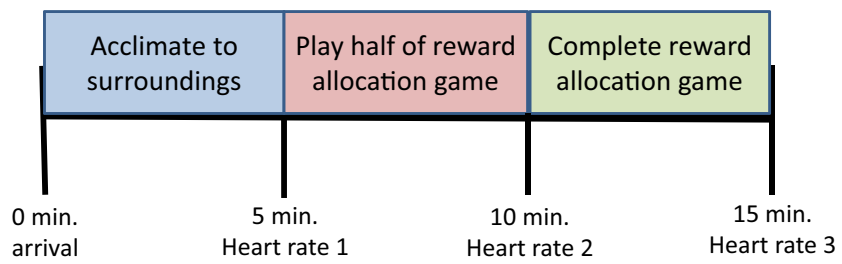

Fig. 1 Timeline of experimental procedure and heart rate data collection

\section{Study Two Results}

A linear regression was conducted using self-reported social strategy (prosocial, coercive, and bi-strategic) and sex to predict self-reported dominance. Prosocial strategies emerged as the only significant predictor of self-reported dominance $(F(1,49)=$ $6.69, p=.04, \beta=.46)$. When this was examined separately for males and females, selfreported prosocial skills predicted self-reported dominance for males $(F(1,28)=5.49$, $p=.03, \beta=.41)$, but did not for females $(F(1,20)=.44, p=.52, \beta=.15)$.

The heart rate scores for the resource allocation task on first day of camp were examined. To determine whether sex and personality were associated with heart rate change over the course of the task, a series of linear regressions were conducted using sex and personality traits to predict heart rate change between time one and time three of the reward allocation task. Results revealed that Affiliativeness predicted heart rate change $(F(1,49)=5.35, p=.025, \beta=-.32)$. Follow-up analysis revealed that this was true for males $(F(1,27)=10.13, p=.004, \beta=-.53)$, but not females $(F(1,19)=.00, p=.98, \beta=.01)$. In addition, Negative Affect predicted heart rate change $(F(1,49)=12.33, p=.00, \beta=.46)$.

Heart rate scores were also examined for the resource allocation task on final day of camp. To determine whether sex and personality were associated with heart rate change, a series of linear regressions were conducted using sex and personality traits to predict heart rate change between time one and time three of the reward allocation task. Results revealed that Negative Affect predicted heart rate change $(F(1,47)=5.50$, $p=.02, \beta=-.33)$. Correlations also revealed that winning the reward allocation task (those who received the most money allotted to them) at the end of the task was related to activation control $(r=.33, p=.02)$ and pleasure sensitivity $(r=.34, p=.01)$.

\section{Study Two Discussion}

In study two, social dominance was related to prosocial skills but not coercive strategies'. Once again, it may be the length of time between formation of groups and end of camp was not sufficient to elicit coercive strategies. The reward allocation task was used to represent the distribution of resources in everyday life. This is an important implicit part of every hierarchy. The results of the current study reveal that when individuals first meet, decreased affiliation was associated with increasing heart rate throughout the task, but only for males. In addition, increased negative affect was associated with increasing heart rate for males and females. It is possible negative affect in participants and the decreased desire to affiliate with others created an increase in arousal response to the game based on opportunity and challenge (Nesse et al. 2007).

When examining the change in heart rate throughout the second task, it was discovered that increased negative affect was related to a decrease in heart rate. In this 
instance, it may be that negative affect is related to sadness or rejection due to the more established hierarchy (Gunther Moor et al. 2010; Kreibig, et al. 2007).

Finally, winning the second task was related to the personality traits of activation control and increased pleasure sensitivity. Dominance (in this case, winning the task and obtaining resources) is related to attentional control and emotionality. Attentional control and activation control are both components of effortful control and emotionality is related to pleasure sensitivity. Once again it appears that the individuals who obtain resources have certain personality traits that may allow them to use the appropriate strategy at the appropriate time, and inhibit the desire to act impulsively.

\section{Study Three}

This study attempted to replicate and extend the previous findings by exploring the role of the HPA axis (via salivary cortisol) in adolescent social hierarchies. This study employed the experimental reward allocation task used in the previous study to examine how social status and sex differences were related to changes in HPA axis activity in an established hierarchy. In addition, this study examined qualities associated with social dominance, in order to determine individual differences in HPA system reaction to psychosocial contexts. Overall, this study aimed to determine whether socially dominant (i.e., bi-strategic) individuals would show greater HPA activity than subordinate individuals to resource allocation.

\section{Specific Hypotheses}

Individuals ranked as dominant by their peers were expected to score higher on bistrategic controlling strategies as seen in Hawley and colleagues' work (2003; 2007). Those who were ranked as high in dominance were expected to have the greatest change in cortisol levels after the reward allocation task. As seen in previous literature (Stroud et al. 2002), females were expected to show a stronger HPA response to the experimental social interaction than males. The dominant females were expected to show the strongest cortisol response because of their increased focus on being socially visible (see Hawley, et al. 2002).

\section{Study Three Method}

\section{Session One}

Participants Participants were students in grades 10th, 11th, and 12th from a high school in rural central United States. Most students were middle to low socio-economic status. No ethnicity data was recorded, although city census data show the majority as Caucasian. Every student in grades 10th, 11th, and 12th was asked to participate through informed consent forms distributed to parents and informed assent forms given during the students' English classes. Thirty-five adolescents (17 male, 18 female) participated in session one (13 in 10th grade, 7 male; 12 in 11 th grade, 7 male; and 10 in 12th grade, 3 male). 
Materials and Procedure Only those for whom both parental consent and child assent was attained were included in the study. Participants were given a list of all students in their grade that had returned the consent forms. Participants were asked to rank those students as popular or unpopular according to the procedure described above, and were used to organize students into groups for the second part of the study. Once again, previous literature has shown perceived popular rankings to be the same as social dominance for adolescents especially when referring to the use of social strategies (Hawley et al. 2007); therefore, for clarity, social dominance is used in this paper. Participants also completed a demographic questionnaire, a ten-item personality inventory (TIPI) (Gosling et al. 2003) and, a modified version of the Resource-Control Strategies Inventory (RSCI) (Hawley 2003a, b; 2007; 2014).

\section{Session Two}

Participants Thirty adolescents (16 male) who completed the first session participated in session two, which took place approximately 2 weeks after session one. Five participants that completed the first session did not take part in the second session because they had changed residence or were not attending school during data collection. These five individuals were evenly distributed across social status ranking showing that status did not impact the attrition rate.

\section{Materials and Procedure}

Salivary Cortisol Participants were screened and excluded from the study for all potential confounds to cortisol (e.g., sleep, exercise, tobacco use, caffeine, and food) at least $1 \mathrm{~h}$ prior to collection of saliva (Kelly et al. 2008). Saliva was obtained from participants by instructing them to place a $1 \times 4 \mathrm{CM}$ absorbent swab in their mouths and saturate it with saliva for approximately 1-2 min. The swabs were collected, labeled, and frozen at $-20{ }^{\circ} \mathrm{C}$ until they assayed for cortisol.

Saliva was taken for cortisol as they arrived (pre-task sample), immediately following the reward allocation task (post-task sample), and 15 min following the task (15 min post-task sample). Sampling intervals were selected to best reflect the activity of the HPA axis to challenges (Gordis et al. 2006).

On the day of testing saliva samples were centrifuged at 3,000 rpm for $15 \mathrm{~min}$ to remove mucins. Following Granger and colleagues (2007), samples were assayed for cortisol (enzyme immunoassay) using commercially available reagents (Salimetrics, State College, PA). Cortisol levels were reported in micrograms per deciliter (ug/dL). These assays have average intra- and inter-assay coefficients of variation less than $6 \%$ and $10 \%$ respectively.

Experimental Task The reward allocation task was conducted as in Study 2, with the exception that the amount was determined based on the group size $(\$ 30=3$ participants, $\$ 40=4$ participants, and $\$ 50=5$ participants). Participants were divided by the experimenter into groups of three, four, or five. The placement of the participants was based 
on the popularity ranking that was conducted in session one. Without the participants' knowledge, they were placed in groups with high and low ranked students or in groups with middle ranking students. In general two high and two low dominant students were placed together or four middle ranking students. In some cases, however, the groups consisted of three or five. In those instances, the group was composed of all middle ranking or had more low dominant ranked than high dominant ranked students. The individual in each group that received the most money during the task was entered in a drawing to win a $\$ 50$ gift card to help insure the saliency of the task.

\section{Study Three Results}

\section{Session One}

Session one employed the use of mean scores on the dominant ranking questionnaires (Hawley, et al. 2007). Participants average dominant rankings ranged from 1.50 (low dominance) to 4.60 (high dominance) with a mean score of 3.02. The Resource Strategies Control Inventory (Hawley 2003a, b) was used in order to determine if individuals that were ranked as highly dominant are reported as bi-strategic controllers. The scores for bi-strategic controllers were configured using the sum of prosocial questions and coercive questions. This method is a deviation from previous work by Hawley $(2003 a, b)$ in which percentiles were used. Due to the small sample size, summed scores from participants use of both strategies was used for this study.

A series of correlation analyses were conducted in order to determine if individuals that are highly popular are reported as high in bi-strategic controller strategies. Dominance was significantly correlated with coercive strategies $(\mathrm{r}=.44, \mathrm{p}<.01)$, prosocial strategies $(\mathrm{r}=.58, \mathrm{p}<.00)$, bi-strategic strategies $(\mathrm{r}=.62, p<.00)$, and extraversion $(r=.61, p<.00)$ (See Table 1$)$. In addition, overt aggression was significantly correlated with conscientiousness $(r=.36, p<.05)$.

\section{Session Two}

Cortisol scores were positively skewed. In all analyses, we used a natural log transformation for cortisol scores to normalize the distributions (see Gordis et al. 2006). In order to test the interaction of cortisol and sex, three paired sample t-tests were conducted with a Bonferroni correction. There were significant effects between sex and salivary cortisol at time one, two, and three. Girls had higher salivary cortisol levels at all three times (Fig. 2).

In order to probe the relationship between of average dominance and salivary cortisol, the average dominance was divided into groups based on the 30-40-30\% (dominant, middle, and subordinate) class ranking categories. Because of attrition from session one to session two, each group (dominant, middle, subordinate) had ten individuals. The salivary cortisol scores were averaged within these categories and a paired sample $t$-test was conducted. Results revealed middle ranked individuals were significantly different from subordinate and dominant individuals $(t=4.72, p=.04, t=$ $8.52, p=.01)$. There was not a significant difference between the subordinate and 
Table 1 Popularity correlations

\begin{tabular}{lllll}
\hline & Coercive strategies & Prosocial strategies & Bi-strategic strategies & Extraversion \\
\hline Average popularity & $438^{*}$ & $.579 * *$ & $.616^{* *}$ & $.607^{* *}$ \\
\hline
\end{tabular}

**. Correlation is significant at the 0.01 level (2-tailed)

*. Correlation is significant at the 0.05 level (2-tailed)

dominant group. The middle ranked individuals had the lowest levels of salivary cortisol throughout the task (See Fig. 3).

In order to determine whether dominance and sex were predictive of cortisol, a series of regression analyses were conducted using average dominance and sex as predictors and overall change in cortisol levels from pre-task to post-task. The change scores consisted of a simple subtraction of salivary cortisol levels from pre-task (time 1) to immediate post-task (time 2), from immediate post-task to 15 -min post-task (time 3 ), and from pre-task (time 1) to 15-min post-task (time 3 ). Girls' average dominance rank predicted cortisol change between time two and time three $(F(1,12)=7.81, p=.02$, $\beta=.63)$, but boys' dominance was not a significant predictor $(F(1,14)=.01, p=.92, \beta=$ $-.03)$.

To determine whether there was a relationship between dominance and most money earned during the reward allocation task, a linear regression was conducted using dominance to predict winning the most money and revealed that dominance predicted winning the task $(F(1,27)=5.09, p=.04, \beta=.52)$. In addition, sex differences were examined in relation to personality traits and winning the most money. Most money won was related to extraversion $(F(1,27)=7.37, p=.01, \beta=.46)$. Follow-up test revealed this was true for females $(F(1,12)=13.30, p=.00, \beta=.70)$ but not for males $(F(1,15)=.80$, $p=.39, \beta=.23$ ). No strategy usage was related to winning the most money.

\section{Study Three Discussion}

The findings of study three were not consistent with studies one and two. The findings in study three showed that dominance is related to extroversion as well as the use of

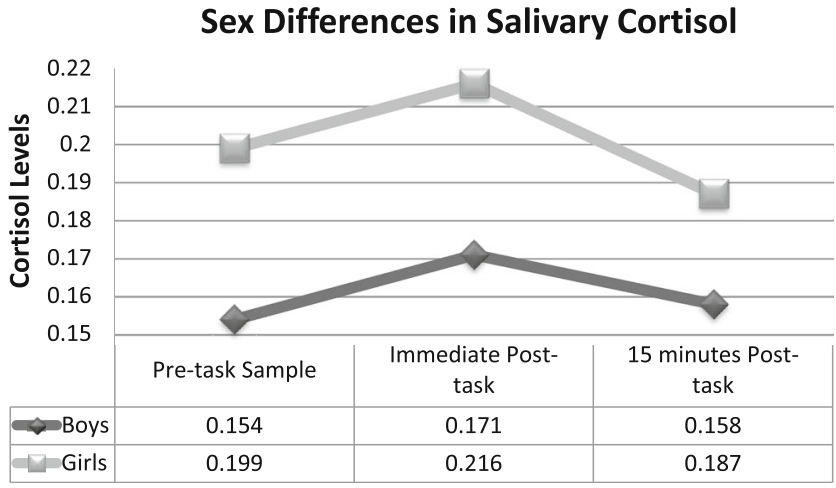

Fig. 2 Sex differences in salivary cortisol 


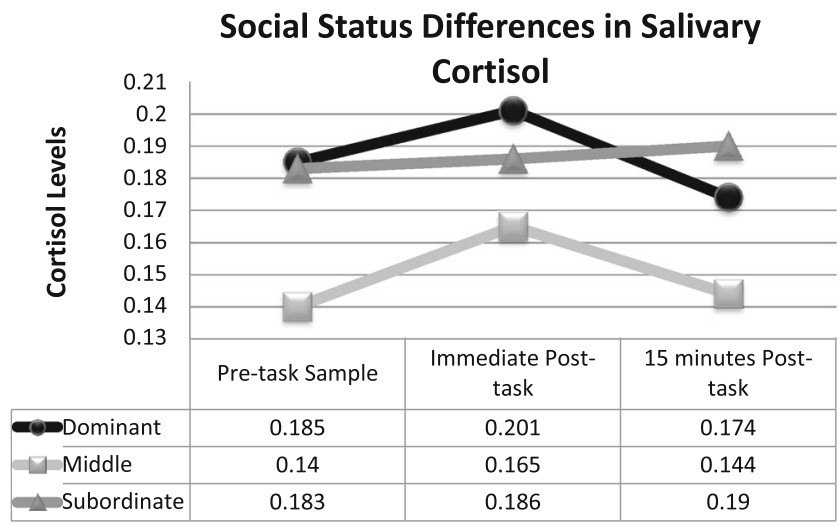

Fig. 3 Social status differences in salivary cortisol

prosocial and coercive strategies. This is consistent with previous studies (Hawley 2003a, b; van der Linden, et al. 2010). It may be that this was apparent only in study three because the hierarchy was more established and the group consisted of older adolescents. In addition, overt aggression was related to conscientiousness. This may reflect the strategic use of overt aggression (Hawley and Geldhof 2012).

Sex differences in HPA activity have been largely mixed. While some laboratory tasks have shown that males have higher cortisol levels (Dickerson and Kemeny 2004; Stroud et al. 2002), many of these did not involve tasks that explicitly addressed potential loss of status and/or social support. In the current study, females displayed higher cortisol levels during the entire reward allocation task, consistent with previous literature (Weekes et al. 2008). The most dominant females had the greatest response to the reward allocation task. The relative instability of female hierarchies (SavinWilliams 1978), and sensitivity to issues surrounding same-sex friendships (Benenson and Christakos 2003), may have potentially contributed to elevated cortisol levels for girls, especially those in dominant positions, due to arousal arising during anticipation of the reward allocation task.

\section{General Discussion}

Social status may play an important role in the stress response systems reactions to psychosocial challenges, particularly during adolescence. The results from study three, with an established hierarchy, showed that, as predicted, as the dominance level increased, the use of prosocial and coercive (relational or overt aggression) strategies increased, consistent with previous literature (Hawley 2014). These findings suggest that, on average, social dominance is often linked with the combination of these strategies and this appears to allow for the greatest control of resources and social prominence (Hawley et al. 2007). The lack of this effect in studies one and two may reflect the differences in establishment of the hierarchies.

Temperament/personality was also explored in relation to dominance. Temperament/ personality traits can predict those most motivated by psychosocial challenges. In the current studies, extraversion/surgency and openness to experience was associated with 
dominance ratings from peers. This is consistent with previous literature that shows extraversion and openness to experience impacts aspects of friendship and social likeability (Akrami and Ekehammar 2006; van der Linden et al. 2010; Witvliet et al. 2010; Young and Bradley 1998). Extraverted individuals are often socially visible and known by all members of the group, and engage in behaviors that are associated with gaining social standing (Davis et al. 1999). In addition, they are more socially motivated and therefore are more interested in controlling social resources (John et al. 1994). Other areas of temperament/personality that were observed to be related to dominance were emotional understanding and aspects of effortful control. For example, emotional stability, affiliation, activation control, and conscientiousness were related to some aspects of dominance. Previous literature has suggested that these aspects are not only useful in relationships and social status (Pellegrini, et al. 2011; van der Linden et al. 2010) but, may be helpful in the strategic use of social skills in order to gain resources while maintaining a positive reputation with those outside the group (Hawley and Geldhof 2012; Hawley, et al. 2007; van der Linden, et al. 2010; Young and Bradley 1998). This can best be explained by the Social Centrality Hypothesis, in which aggressors may be very socially skilled and socially appealing and the benefit of associating with them may outweigh the costs (Hawley 2008).

Adolescence is a time of learning to navigate same-sex hierarchies, and sex differences in social behavior are often at their peak during this developmental period (Ellis et al. 2012; Geary 2010). Thus, it is important to take these differences into consideration when examining contexts most likely to activate the stress response system. Study two showed that affiliation (for males only) and negative affect were related to ANS activation. Negative affect was related to increased heart rate during the reward allocation task at the beginning of camp and related to decreased heart rate at the end of camp. At the beginning of the week, negative affect combined with heart rate increase may have been due to the challenge and opportunity presented in the task (Nesse et al. 2007). At the end of the week, negative affect and heart rate decrease might have been related to peer rejection based on the more established hierarchy (Gunther Moor et al. 2010; Kreibig, et al. 2007). Previous studies have shown that ANS activation is related to peer rejection and negative affect in adolescents (Stroud, et al. 2009). The importance of affiliation may also elicit the response of the ANS if individuals are concerned with interest in bonding (Kivlighan and Granger 2006), which at the beginning of camp may be less important due to a lack of established hierarchy.

The findings of study three suggest an anticipatory period could signal an opportunity for social gains or losses, as the outcome of the task was relatively novel and unpredictable and was likely socially salient, all factors documented to elicit cortisol responses (Dickerson and Kemeny 2004; Huether 1998). Cortisol also facilitates attentional focus (Sapolsky et al. 2000), and in this context, possibly attention to subtle social cues can be used to gain or maintain status in the social hierarchy.

Interpreting differences in cortisol responses in relation to attentional focus may further be supported by examination of dominant girls' responses to the reward allocation task. In the third study, the amount of money won during the reward allocation task increased as a function of girls' perceived dominance. When this finding is examined in relation to measured salivary cortisol levels over time, it appears that dominant girls were more aroused during the beginning of the task (higher cortisol) but became less aroused (lower cortisol) after winning or beginning to win. These results 
were consistent with previous work conducted by Davis et al. (1999) in which a larger initial increase in cortisol was observed in extroverted children, with a subsequent decline in cortisol as the school year proceeded. Similarly, the third study showed that dominant girls (also more likely to be extroverted) showed a similar profile of initial elevation and then a decline in cortisol levels. In dominant individuals, cortisol may facilitate attentional focus toward aspects of the social situation that will best yield social rewards and attainment of social resources. Increased activation of the HPA axis potentially represents one avenue through which dominant girls prepare themselves for the potential of loss or maintenance of their position in the social hierarchy. For example, Taylor's tend-and-befriend theory (Taylor et al. 2000) suggests that perceived gaps in social support facilitates HPA activity as well as oxytocin release and affiliation. Females are more likely to affiliate in stressful situations, and the impact of social support is likely a more salient feature in female resource control (Taylor 2006). Affiliative efforts that are met with quality social support are associated with decreases in stress system activity. It is also possible that the rise in cortisol may be due to positive anticipation and is not necessarily a product of negative affect (Fortunato et al. 2008).

One useful interpretation of the results from the current study would be to frame cortisol responses in dominant girls as a product of active status striving. Synthesis and release of cortisol, as well as many other products of the stress response system, represent physiological resources that are provisioned to assist with the cognitive and behavioral features (e.g., attentional focus, arousal and anticipation of loss or gain) that potentially facilitate movement up and down the social ladder, or maintain the status quo (Flinn et al. 2011). Because cortisol responses have been linked to anticipation of events involving both positive and negative expectations (Flinn 2006), and the potential for gain or loss, particularly of social resources, (Nesse, et al. 2007; Taylor et al. 2000) it would be reasonable to predict individuals that fall somewhere in the middle of the social hierarchy to show weaker cortisol responses than those ranked closer to the top or bottom, who have more to gain (those at the bottom) or lose (those at the top), respectively. Results from the current study were consistent with this prediction dominant and subordinate individuals had greater cortisol levels throughout the reward allocation task compared to those ranked in the middle. Based on previous literature (Gesquiere, et al. 2011; Sapolsky 2004), the middle-ranked individuals might not be as physiologically responsive to the reward allocation task, as they neither need to maintain nor lose status. It is important to note that most middle-ranked individuals interacted during the allocation task with other middle-ranked individuals.

Taken together it appears that social dominance is related to prosocial, coercive, and aggressive strategies, and related to temperament/personality qualities that allow them to display them at the appropriate times. The studies also suggest that, while the stress response systems work in concert to influence social behavior, the ANS and HPA axis exert functionally different effects. The ANS is more activated under conditions of mild social threat, while both dominant and subordinate individuals showed greater HPA activity relative to middle-ranked individuals in Study 3. Together, these findings suggest that while the ANS is, in this context, presumably attuned to conditions that may involve further loss of status, the HPA axis manages both threat and opportunity (Nesse et al. 2007). This is seen more in female dominants, as the dominant position may be more challenging to secure, thus necessitating attention and vigilance to social information. 


\section{Limitations}

These studies serve as an exploratory look into dominance and associated stress response activity during adolescence. They aid in the understanding of social hierarchies, characteristics of status, and stress response to social dynamics. One limitation of the current studies is that it is difficult to differentiate between the effects of a novel social environment and participants' responses to social hierarchies. This concern is reduced, however, given that study three, using an established hierarchy found similar results. Another limitation of the current studies is the lack of diversity of the sample populations as well as the small sample sizes. Future studies should be conducted in large schools or camps as well as in different cultures and sub-cultures, helping to determine if there are situational or cultural differences related to physiological reactions to social hierarchy contexts in adolescence. Other limitations are seen in the physiological measures used. Heart rate is a not often a conclusive measurement especially when used in problem solving (Elias 1970), and the measure used to collect heart rate was not of the quality to allow more intricate comparisons (as technology such as a BIOPAC would have allowed). The method of heart rate collection was chosen due to the physical circumstances of the summer camp that did not allow for the use of more sophisticated equipment. In addition, a dual stress response system approach (HPA and ANS) would have provided a more complete picture of physiological responses to these hierarchical systems (Bauer et al. 2002). Additionally, the participants in this study were not questioned concerning possible oral contraceptive usage that may have an effect on measured cortisol levels (Granger et al. 2012).

\section{Conclusion and Future Directions}

Numerous studies assessing the relationship between physiological reactivity, social hierarchies, and dominance have been conducted in recent decades, providing insight as to how social challenges have the potential to uniquely influence physiological activity of the stress response system. Collectively, the available literature on the relationship between social hierarchies and stress system physiology is inconclusive, highlighting the need for additional work in underrepresented research populations such as adolescents. To that aim, the current study investigated the relationship between social hierarchies and physiological activity in adolescents. These results may provide insight as to which individuals in social hierarchies are most physiologically responsive to social anticipation and interaction.

\section{References}

Akrami, N., \& Ekehammar, B. (2006). Right-wing authoritarianism and social dominance orientation: their roots in big-five personality factors and facets. Journal of Individual Differences, 27(3), 117-126. doi:10. 1027/1614-0001.27.3.117.

Bauer, A. M., Quas, J. A., \& Boyce, W. T. (2002). Associations between physiological reactivityand children's behavior: advantages of the multisystem approach. Journal of Developmental and Behavioral Pediatrics, 23, 102-113. 
Benenson, J. F., \& Christakos, A. (2003). The greater fragility of females' versus males' closest same-sex friendships. Child Development, 74, 1123-1129.

Berntson, G. G., Cacioppo, J. T., \& Quigley, K. S. (1991). Autonomic determinism: the modes of autonomic control, the doctrine of autonomic space, and the laws of autonomic control. Psychological Review, 98, 459-487.

Blake, J. J., Kim, E. S., \& Lease, A. M. (2011). Exploring the incremental validity of nonverbal social aggression: the utility of peer nominations. Merrill-Palmer Quarterly, 57(3), 293-318. doi:10.1353/mpq. 2011.0015

Boyce, W., \& Ellis, B. J. (2005). Biological sensitivity to context: I. An evolutionary-developmental theory of the origins and functions of stress reactivity. Development and Psychopathology, 17, 271-301. doi:10. 1017/S0954579405050145.

Bruce, J., Davis, E. P., \& Gunnar, M. R. (2002). Individual differences in children's cortisol response to the beginning of a new school year. Psychoneuroendocrinology, 27(6), 635-650. doi:10.1016/s03064530(01)00031-2.

Capaldi, D. M., \& Rothbart, M. K. (1992). Development and validation of an early adolescent temperament measure. The Journal of Early Adolescence, 12(2), 153-173. doi:10.1177/0272431692012002002.

Chamove, A. S., \& Bowman, R. E. (1978). Rhesus plasma cortisol response at four dominance positions. Aggressive Behavior, 4(1), 43-55. doi:10.1002/1098-2337(1978)4:1<43::aid-ab2480040105>3.0.co;2-o.

Cloutier, J. J., Norman, G. J., Li, T. T., \& Berntson, G. G. (2013). Person perception and autonomic nervous system response: the costs and benefits of possessing a high social status. Biological Psychology, 92(2), 301-305. doi:10.1016/j.biopsycho.2012.09.006.

Davis, E. P., Donzella, B., Krueger, W. K., \& Gunnar, M. R. (1999). The start of a new school year: individual differences in salivary cortisol response in relation to child temperament. Developmental Psychobiology, 35(3), 188-196. doi:10.1002/(sici)1098-2302(199911)35:3<188::aid-dev3>3.0.co;2-k.

De Pascalis, V., Fiore, A., \& Sparita, A. (1996). Personality, event-related potential (ERP) and heart rate (HR): an investigation of Gray's theory. Personality and Individual Differences, 20(6), 733-746. doi:10.1016/ 0191-8869(96)00016-5.

De Pascalis, V., Strelau, J., \& Zawadzki, B. (1999). The effect of temperamental traits on event-related potentials, heart rate and reaction time. Personality and Individual Differences, 26(3), 441-465. doi:10. 1016/S0191-8869(98)00151-2.

Dickerson, S. S., \& Kemeny, M. E. (2004). Acute stressors and cortisol responses: a theoretical integration and synthesis of laboratory research. Psychological Bulletin, 130(3), 355-391. doi:10.1037/0033-2909.130.3. 355.

Eisenberg, N., Fabes, R. A., Miller, P. A., Fultz, J., Shell, R., Mathy, R. M., \& Reno, R. R. (1989). Relation of sympathy and personal distress to prosocial behavior: a multimethod study. Journal of Personality and Social Psychology, 57(1), 55-66. doi:10.1037/0022-3514.57.1.55.

Elias, M. F. (1970). Heart rate, skin potential response, and latency of overt response, as indicators of problem recognition and solution. Psychonomic Science, 18(6), 337-339.

Ellis, B. J., \& Del Giudice, M. (2014). Beyond allostatic load: rethinking the role of stress in regulating human development. Development and Psychopathology, 26, 1-20. doi:10.1017/s0954579413.

Ellis, B. J., Del Giudice, M., Dishion, T. J., Figueredo, A. J., Gray, P., Griskevicius, V., Hawley, P. J., Jacobs, W. J., James, J., Volk, A. A., \& Wilson, D. S. (2012). The evolutionary basis of risky adolescent behavior: implications for science, policy, and practice. Developmental Psychology, 48, 598-623.

Flinn, M. V. (2006). Evolution and ontogeny of stress response to social challenges in the human child. Developmental Review, 26(2), 138-174. doi:10.1016/j.dr.2006.02.003.

Flinn, M. V., Quinlan, R. L., Ward, C. V., \& Coe, M. K. (2007). Evolution of the human family: cooperative males, long social childhoods, smart mothers, and extended kin networks. In C. Salmon \& T. Shackelford (Eds.), Family relationships (pp. 16-38). Oxford: Oxford University Press.

Flinn, M. V., Nepomnaschy, P. A., Muehlenbein, M. P., \& Ponzi, D. (2011). Evolutionary functions of early social modulation of hypothalamic-pituitary-adrenal axis development in humans. Neuroscience and Biobehavioral Reviews, 35, 1611-1629.

Fortunato, C. K., Dribin, A. E., Granger, D. A., \& Buss, K. A. (2008). Salivary alpha-amylase and cortisol in toddlers: differential relations to affective behavior. Developmental Psychobiology, 50(8), 807-818. doi: $10.1002 / \operatorname{dev} .20326$.

Fox, H. E., White, S. A., Kao, M. H. F., \& Fernald, R. D. (1997). Stress and dominance in a social fish. The Journal of Neuroscience, 17(16), 6463-6469.

Frankenhaeuser, M. (1982). Challenge-control interaction as reflected in sympathetic-adrenal and pituitaryadrenal activity: comparison between the sexes. Scandinavian Journal of Psychology Supplement, 1, 158164. 
Geary, D. C. (2010). Male, female: the evolution of human sex differences (2nd ed.). Washington, DC: American Psychological Association.

Geary, D. C., \& Flinn, M. V. (2002). Sex differences in behavioral and hormonal response to social threat: commentary on Taylor et al. (2000). Psychological Review, 109(4), 745-750.

Geary, D. C., Byrd-Craven, J., Hoard, M. K., Vigil, J., \& Numtee, C. (2003). Evolution and development of boys' social behavior. Developmental Review, 23(4), 444 470. doi:10.1016/j.dr.2003.08.001.

Gesquiere, L. R., Learn, N. H., Simao, M. C., Onyango, P. O., Alberts, S. C., \& Altmann, J. (2011). Life at the top: rank and stress in wild male baboons. Science, 333(6040), 357-360. doi:10.1126/ science. 1207120.

Gordis, E. B., Granger, D. A., Susman, E. J., \& Trickett, P. K. (2006). Asymmetry between salivary cortisol and alpha-amylase reactivity to stress: relation to aggressive behavior in adolescents. Psychoneuroendocrinology, 31(2006), 976-987.

Gosling, S. D., Rentfrow, P. J., \& Swann, W. B., Jr. (2003). A very brief measure of the big five personality domains. Journal of Research in Personality, 37, 504-528.

Granger, D. A., Kiviligan, K. T., Fortunato, C., Harmon, A. G., Hibel, L. C., Schwartz, E. B., \& Whembolua, G. L. (2007). Integration of salivary biomarkers into developmental and behaviorally-oriented research: problems and solutions for collecting specimens. Physiology and Behavior, 92, 583-590.

Granger, D. A., Fortunato, C. K., Beltzer, E. K., Virag, M., Bright, M. A., \& Out, D. (2012). Focus on methodology: salivary bioscience and research on adolescence: an integrated perspective. Journal of Adolescence. doi:10.1016/j.adolescence.2012.01.005.

Gunther Moor, B., Crone, E. A., \& van der Molen, M. W. (2010). The heartbrake of social rejection: heart rate deceleration in response to unexpected peer rejection. Psychological Science, 21(9), 1326-1333. doi:10. $1177 / 0956797610379236$.

Hawley, P.H. (2003). Evolution and personality: a new look at Machiavellianism. Handbook of personality development [e-book]. 147-161.

Hawley, P. H. (2003b). Strategies of control, aggression, and morality in preschoolers: an evolutionary perspective. Journal of Experimental Child Psychology, 85, 213-235.

Hawley, P. H. (2007). Social dominance in childhood and adolescence: why social competence and aggression may go hand in hand. In: Aggression and adaptation: the bright side to bad behavior, ed. P. H. Hawley, T. D. Little \& P. C. Rodkin, pp. 1-29. Erlbaum.

Hawley, P. H. (2008). Competition and social and personality development: some consequences of taking Darwin seriously. Anuario De Psicología, 39(2), 193-208.

Hawley, P. H. (2014). Ontogeny and social dominance: a developmental view of human power patterns. Evolutionary Psychology, 12(2), 318-342.

Hawley, P. H., \& Geldhof, G. (2012). Preschoolers' social dominance, moral cognition, and moral behavior: an evolutionary perspective. Journal of Experimental Child Psychology, 112(1), 18-35. doi:10.1016/j.jecp. 2011.10.004.

Hawley, P. H., Little, T. D., \& Pasupathi, M. (2002). Winning friends and influencing peers: strategies of peer influence in late childhood. International Journal of Behavioral Development, 26(5), 466-474. doi:10. 1080/01650250143000427.

Hawley, P. H., Little, T. D., \& Card, N. A. (2007). The allure of a mean friend: relationship quality and processes of aggressive adolescents with prosocial skills. International Journal of Behavioral Development, 31(2), 170-180. doi:10.1177/0165025407074630.

Hellhammer, K. H., Buchtal, J., Gutberlet, I., \& Kirschbaum, C. (1997). Social hierarchy and adrenocortical stress reactivity in men. Psychoneuroendocrinology, 22(8), 643-650. doi:10.1016/s0306-4530(97)000632.

Hellhammer, D. H., Wüst, S., \& Kudielka, B. M. (2009). Salivary cortisol as a biomarker in stress research. Psychoneuroendocrinology, 34(2), 163-171. doi:10.1016/j.psyneuen.2008.10.026.

Huether, G. (1998). Stress and the adaptive self-organization of neuronal connectivity during early childhood. International Journal of Developmental Neuroscience, 16(3-4), 297-306. doi:10.1016/s0736-5748(98) 00023-9.

John, O. P., Caspi, A., Robins, R. W., \& Moffitt, T. E. (1994). The 'little five': exploring the nomological network of the five-factor model of personality in adolescent boys. Child Development, 65(1), 160-178. doi: $10.2307 / 1131373$.

Kelly, S. J., Young, R., Sweeting, H., Fischer, J. E., \& West, P. (2008). Levels and confounders of morning cortisol collected from adolescents in a naturalistic (school) setting. Psychoneuroendocrinology, 33(9), 1257-1268. doi:10.1016/j.psyneuen.2008.06.010.

Kivlighan, K. T., \& Granger, D. A. (2006). Stress responsivity to competition: gender and experiential differences in salivary alpha-amylase and cortisol activity. Psychoneuroendocrinology, 31, 703-714. 
Kreibig, S. D., Wilhelm, F. H., Roth, W. T., \& Gross, J. J. (2007). Cardiovascular, electrodermal, and respiratory response patterns to fear- and sadness-inducing films. Psychophysiology, 44(5), 787-806. doi:10.1111/j.1469-8986.2007.00550.x.

Nesse, R. M., Bhatnagar, S., \& Young, E. A. (2007). Evolutionary origins and functions of the stress response. Encyclopedia of Stress, 1, 965-970.

O'Brein, D. T. (2014). An evolutionary model of the environmental conditions that shape the development of prosocialilty. Evolutionary Psychology, 12(2), 386-402.

Ostner, J., Heistermann, M., \& Schülke, O. (2008). Dominance, aggression and physiological stress in wild male Assamese macaques (Macaca assamensis). Hormones and Behavior, 54(5), 613-619. doi:10.1016/j. yhbeh.2008.05.020.

Pellegrini, A. D., Van Ryzin, M. J., Roseth, C., Bohn-Gettler, C., Dupuis, D., Hickey, M., \& Peshkam, A. (2011). Behavioral and social cognitive processes in preschool children's social dominance. Aggressive Behavior, 37(3), 248-257. doi:10.1002/ab.20385.

Peters, M. L., Godaert, G. L. R., Ballieus, R. E., van Vliet, M., Willemsen, J. J., Sweep, F. C. J., \& Heijen, C. J. (1998). Cardiovascular and endocrine responses to experimental stress: effects of mental effort and controllability. Psychoneuroendocrinology, 23, 1-17.

Poisbleau, M., Fritz, H., Guillon, N., \& Chastel, O. (2005). Linear social dominance hierarchy and corticosterone responses in male mallards and pintails. Hormones and Behavior, 47(4), 485-492. doi:10.1016/j. yhbeh.2005.01.001.

Pratto, F., Sidanius, J., Stallworth, L. M., \& Malle, B. F. (1994). Social dominance orientation: a personality variable predicting social and political attitudes. Journal of Personality and Social Psychology, 67(4), 741-763. doi:10.1037/0022-3514.67.4.741.

Rose, A. J., Swenson, L. P., \& Carlson, W. (2004). Friendships of aggressive youth: considering the influences of being disliked and of being perceived as popular. Journal of Experimental Child Psychology, 88(1), 25-45. doi:10.1016/j.jecp.2004.02.005.

Roseth, C. J., Pellegrini, A. D., Dupuis, D. N., Bohn, C. M., Hickey, M. C., Hilk, C. L., \& Peshkam, A. (2011). Preschoolers' bistrategic resource control, reconciliation, and peer regard. Social Development, 20(1), 185-211. doi:10.1111/j.1467-9507.2010.00579.x.

Sapolsky, R. M. (2004). Social status and health in humans and other animals. Annual Review of Anthropology, 33(1), 393-418. doi:10.1146/annurev.anthro.33.070203.144000.

Sapolsky, R. M. (2005). The influence of social hierarchy on primate health. Science, 308, 648-652.

Sapolsky, R. M., Romero, L. M., \& Munck, A. U. (2000). How do glucocorticoids influence stress responses? Integrating permissive, suppressive, stimulatory, and preparative actions. Endocrine Reviews, 21, 55-89.

Savin-Williams, R. C. (1978). Dominance-submission behaviors and hierarchies in young adolescents at a summer camp: predictors, styles, and sex differences. 38 .

Savin-Williams, R. C. (1979). Dominance hierarchies in groups of early adolescents. Child Development, 50, 923-935.

Scheepers, D., \& Ellemers, N. (2005). When the pressure is up: the assessment of social identity threat in low and high status groups. Journal of Experimental Social Psychology, 41(2), 192-200. doi:10.1016/j.jesp.2004.06.002.

Spinrad, T. L., Granger, D. A., \& Eisenberg, N. (2007, March). Individual differences in preschoolers' salivary cortisol and alpha-amylase reactivity. Presented at the biennial meeting of thesociety for research on child development (Boston, MA, USA).

Stroud, L. R., Salovey, P., \& Epel, E. S. (2002). Sex differences in stress responses: social rejection versus achievement stress. Biological Psychiatry, 52(4), 318-327. doi:10.1016/s0006-3223(02)01333-1.

Stroud, L. R., Foster, E., Papandonatos, G. D., Handwerger, K., Gragner, D. A., Kivlighan, K. T., \& Niaura, R. (2009). Stress response and the adolescent transition: performance versus peer rejection stressors. Development and Psychopathology, 21, 47-68.

Taylor, S. E. (2006). Tend and befriend: biobehavioral bases of affiliation under stress. Current Directions in Psychological Science, 15, 273-277.

Taylor, S. E., \& Master, S. L. (2011). Social responses to stress: the tend-and-befriend model springer publishing co, New York, NY. Retrieved from http://search.proquest.com/docview/819631113?accountid=4117

Taylor, S. E., Klein, L. C., Lewis, B. P., Gruenewald, T. L., Gurung, R. A. R., \& Updegraff, J. A. (2000). Biobehavioral responses to stress in females: tend-and-befriend, not fight-or-flight. Psychological Review, 107, 411-429.

van der Linden, D., Scholte, R. H. J., Cillessen, A. H. N., Nijenhuis, J. t., \& Seger, E. (2010). Classroom ratings of likeability and popularity are related to the big five and the general factor of personality. Journal of Research in Personality. doi:10.1016/j.jrp.2010.08.007. 
Weekes, N. Y., Lewis, R. S., Goto, S. G., Garrison-Jakel, J., Patel, F., \& Lupien, S. (2008). The effect of an environmental stressor on gender differences on the awakening cortisol response. Psychoneuroendocrinology, 33(6), 766-772. doi:10.1016/j.psyneuen.2008.03.003.

Witvliet, M., Olthof, T., Hoeksma, J. B., Goossens, F. A., Smits, M. S. I., \& Koot, H. M. (2010). Peer group affiliation of children: the role of perceived popularity, likeability, and behavioral similarity in bullying. Social Development, 19(2), 285-303. doi:10.1111/j.1467-9507.2009.00544.x.

Young, M. R. R., \& Bradley, M. T. (1998). Social withdrawal: self-efficacy, happiness, and popularity in introverted and extroverted adolescents. Canadian Journal of School Psychology, 14(1), 21-35. 